\title{
The Analysis of the International Climate Change on Environmental Justice
}

\author{
Wu Xueqin* and Chengping†
}

\begin{abstract}
Since the Club of Rome published "Limits to Growth" in 1972, the environmental problems have caused the attention of people around the world and become a global issue. The international community has also organized special meetings to promote the study of environmental issues. One of the most important meetings is the United Nations Conference on Environment and Development, held every year since 1972. The most important issue is on how to deal with climate change, which has become an international mainstream issue. From the perspective of the environmental justice, the following is a brief analysis of the negotiations on international climate changes, based on the opportunities of the 2009 Copenhagen Summit, the 2010 Cancun Summit and the 2011 South Africa Bender Climate Summit.
\end{abstract}

\footnotetext{
*Dean and Professor of Philosophy, Marxism Institute of Anhui University, China, xqwuad@yahoo.com.cn

†Lecturer of Philosophy, Marxism Institute of Anhui University, China
} 


\section{Environmental Procedural justice: environment priorities or development priorities?}

Environment procedural justice is mainly concerned with developing a variety of decision-making procedures related to environmental protection. The contents include: identifying the basic principles of decision-making, determining the key personnel involved in the decision-making, the basic approach of decisionmaking (such as voting or consultation), and the priority agenda (such as environment or development). ${ }^{1}$

Specific to the international climate-change negotiations, the basic principal for the decision making is the principal of "Common and Differential Liability". This principal has suffered the disapproval of the developed countries overtly or covertly in all the early international climate conferences. Nevertheless, starting from the 1992 "United Nations Framework Convention on Climate Change", the final versions of the 1997 "Kyoto Protocol", the 2007 "Bali Road Map" and the 2009 "Copenhagen Agreement" have all insisted and approved the above-mentioned principal. The fundamental method for the decision making in the international climate change negotiations is through negotiating, as was shown in the Copenhagen Summit. Negotiating representative from 192 countries or regions have attended the summit aiming at discussing the Kyoto Protocol from the phase I Commitment to the successive programs through plenary conferences, sections, group meetings, side-meetings, representatives meetings and council of ministers etc. Both the grandness of the conference scope and the intensiveness of the negotiations are unprecedented. However, there are also special cases of violating the negotiations by the

1 Yang Tongjin, Environmental Ethics: Global Discourse, China Vision, Chongqing: Chongqing Press, 2007, 378. 
developed countries, such as UK, USA and Denmark who concocted the so-called "Danish Proposal" unilaterally which is protested by many developing countries. The Copenhagen Agreement is a result of the negotiations between USA and Brazil, South Africa, India and China (BASIC). Since the Agreement has taken both the interests of the developed countries and those of the developing countries into consideration, it is more likely to obtain the recognition of various interest groups, including the main EU countries, although representatives from some of the developing countries strongly protested that they did not give the opportunities to participate in the final negotiation for the agreement. To pass the Copenhagen Agreement, the conference eventually decided to list the approval countries and the countries with reservations in the Annex of the Agreement. Although the general opinions for the agreement are "too small to be important", "better than nothing" or without legal binding effect," it precisely demonstrates from the procedure the spirit of deliberative democracy: participators of the decision making in the negotiation should be representatives of all participating countries: each country has its own right and responsibility for the proposal, but only the proposals which respect other countries' interests can be passed and become effective legal documents.

The remaining question now is: what is the priority agenda of the climate change negotiations? Is it the protection of the environment, or that of the economic development? This is the source of numerous conflicts between the developed and developing countries, which best reflects the contention of procedural justice on the climate change negotiations.

\footnotetext{
2 Tao Duanfang, Xie Deliang, Liao Zhengjun, "After the summit of world opinion confusion," Global Times, 2009-12-21, 1.
} 
Before solving this problem, we need to explore the essence of the climate change negotiations. International debate on climate change generally contains the contents of scientific cognition, economic assessment and political battles. ${ }^{3}$ Considering that the politics is the concentrated expression of economics and both of them are some kind of interest demands, we can make the contents of the climate change negotiations further simplified into scientific cognition and interest demands. The scientific cognition dimension of the climate change reflects in whether the climate change is caused by anthropogenic greenhouse gas emissions. This issue seemed to be affirmatively answered in 2007, when the United Nations Intergovernmental Panel on Climate Change (IPCC)--Groups consisting of more than 2,300 leading scientists in climate-- released the fourth "Global Climate Change Assessment Report ". This assessment report confirmed that the global warming is an indisputable fact and is mainly caused by the greenhouse gases generated by consuming fossil fuels as a result of human industrial activities. The report noted that in the past 100 years (1906-2005) the global average surface temperature increased by $0.74^{\circ} \mathrm{C}$, while over the past 50 years (1956 to 2005) the increase was $0.65^{\circ} \mathrm{C} .11$ years out of the 12 years in between 1995-2006 were ranked the warmest 12 years since the starting of instrumental observations. In 20th century, global sea level rose about $0.17 \mathrm{~m}$; and the average rising rate is about $1.8 \mathrm{~mm}$ / year between 1961-2003 and $3.1 \mathrm{~mm}$ / year between 1993-2003. The report also predicts that, if the temperature reached $2-3^{\circ} \mathrm{C}$ above the value in 1750 , then $25-40 \%$ of the Earth's ecosystem structure and function would change dramatically. So that heating up $2^{\circ} \mathrm{C}$ was considered as a critical

3 Pan Guhua, "Climate Change: Geopolitical Power Game", Green Leaves, $2008,77$. 
value that can be tolerated by the Earth's natural ecosystems. ${ }^{4}$ We are aware that one should not doubt a report of the scientificity and authoritativity without good reasons. We should also be aware that the report, after all, is written by scientists with national labels, despite that science in it own right has no boundaries. Whether they would use the data out of context, in order to come to the conclusions that meet their own national interests while at the expense of misleading the public opinions of the whole world? This cannot be ruled out. In fact, over 3500 emails stored in a server of a network security company in Tomsk, Sibria, were intercepted by a mysterious hacker in the week before the Copenhagen summit and then exposed just before the Copenhagen summit. Those emails show that the climate experts have collusively manipulated the scientific data in order to support the mainstream view that human activity is the main cause of global warming, and even have tampered with those data unfavorable to the conclusion reached by their own study. This is called the "climate-gate" incident. 5 This event has been continuously enlarged by the global warming skeptics, and became an important basis for their opposition to the global warming mainstream. The wager between the confront parties is too high to be affordable: if the prediction of mainstream is accurate, the inaction will lead to a series of disastrous consequences on the environmental, economics and others; on the other aspect, if the prediction of the mainstream is not accurate, then tens of billions dollars of the global investment to reduce greenhouse gas emissions makes no sense, and the money could have been used on economic recovery.

4 Yang Dongping, China's environmental development report (2010), Beijing: Social Sciences Documents Press, 2010, 181-182.

5 Baidu encyclopedia, "climate door" [EB/OL], http:// baike.Baidu.Com/view / 3046022.HTM, 2010-6-5. 
In some countries, public opinion has already had a subtle change. A poll released by the U.S. media on December 8 showed that only $45 \%$ of the respondents agreed with the views of the mainstream scientists on the climate change, this figure was $56 \%$ two years ago. Of course, some scholars have provided a third perspective: scientific predictions of climate change has uncertainty, but we may wish to view the issue of climate change from the point of paying insurance. In other words, the future of the world may not be flood as the movie shows, but building Noah's Ark in advance is still necessary. This view may help to unite all walks of life consensus. In short, the "climate-gate" incident, a variety of political, economic, and social groups for the consideration of the interests and ideology, get together in groups to drum up support, so the debate goes far beyond the scientific disciplines. ${ }^{6}$ This shows that the climate change is definitely not a simple natural scientific problem, but an important social problem that involved with the vital interests of many countries, and its scientific research orientations are often subject to the consideration of the interests of the community; the climate change is not only an environmental issue, it is a development issue. The climate change should be addressed in the development process, and can only be resolved through common development.

From the arguments on the essence of the aforesaid climate change issues, it can be found that the international order for the climate negotiations is definitely neither fair nor reasonable. The developed countries have more discourse rights and influences in the negotiations, as a result of their strong economic and technological power than the developing countries, whose needs are not fully catered in the related decisions. For example, people in the EU and Japan, who are relatively developed in the economy, can still be

6 Feng Wuyong, "Out of the climate door" [EB/OL]. http://news.xinhuanet.com/ world/ 2009-12/09/content_12614190.htm, 2009-12-09. 
able to hold a high income and live a prosperous life even though their economy stops growing in the future, while people from those countries with large populations, like China and India, would be in hunger and cold once the economy stops growing. As FAO pointed in the "2009 SOFI" report, currently the whole world population amounts to 6.7billion, with 1.02 billion is still suffering the huger and the cold, and majority is from the developing countries, with only 15 million being from the developed countries. ${ }^{7}$ For this reason, it is for their luxury life enjoyment that the developed countries address the priority of the environmental protection for the climate changes. However, for the developing countries, it is from their basic living needs that they should consider the priority of economic development for the climate changes. Climate changes conference should consider both of these two needs by avoiding the "one side fits all" circumstance.

We should bear in mind that, China's participation in the Global climate change negotiation will inevitable face the pressure of the international community on China's environmental protection commitment. As a responsible large country, we need to make a solemn commitment to the international community on the energy saving and emission reduction. There will be a strong difficulty in China's reform. Meanwhile, we can also consider the participation in global climate negotiation as an opportunity in which we can improve our speech rights so as to maintain our development rights and to change our development mode towards achieving the "energy saving" and "environmental friendly" society.

7 Ye Shuhong, "The two giants have a hunger strike for NaBan," Banyuetan: 2009, 90-91. 


\section{Environment of distributive justice: mandatory emission reductions or voluntary mitigation?}

On the global scale, the environment distributive justice is mainly concerned with the equitable distribution of the environmental rights and burdens among countries and regions. Specific to the climate change issue, it is to distribute fairly the right of emission of carbon dioxide and the obligations of emission reduction, so as to control the global warming with the limit of no more than $2{ }^{\circ} \mathrm{C}$ above the temperature at the beginning of the Industrial Revolution. To achieve this, we must return to the principle "common but differentiated responsibilities", because this principle is the allocation of the embodiment of justice to the environment from the content.

The existence of global warming and other environmental problems are mainly the consequences of long-term wanton use of the environment and resources by the developed countries since the Industrial Revolution, while the vast number of developing countries are largely the victims. From the historical point of view, the developed countries' cumulative emissions are much higher than the developing countries. According to the statistics, in the two hundred years between 1750 and 1950, the contribution of human carbon dioxide emissions from the developed countries accounted for 95 percent; from 1950 to 2000, the contribution of the developed countries still accounted for $77 \%$; today, 22 percent of the global total number of developed countries consume $70 \%$ of the world's total annual energy consumption, and produced more than $50 \%$ of the total emission of carbon dioxide. ${ }^{8}$ On the other hand, although some large developing countries' total carbon dioxide emissions are very high in recent years, but the per capita emissions are actually very low. The following data clearly show this: the per capita carbon emissions of the US, the European

8 Du Xiangwan, “Cancun notes,” Guangming Daily, 2010-12-13. 
Union and Japan, and China are 24 tons, about 10 tons, and about 5 tons, respectively. ${ }^{9}$ Therefore, the environmental protection cooperation must follow the "common but differentiated responsibilities" principle, the developed countries must take the lead in the implementation of the mandatory emission reductions, the developing countries can take the measures to voluntary mitigation.

"Common but differentiated responsibilities" principle of the establishment and maintenance went through a difficult period but extraordinary journey. In 1992, the United Nations Environment and Development adopted the United Nations Framework Convention on Climate "(hereinafter referred to as" the Convention "), which is the world's first international treaty to curb global warming on the control of greenhouse gas emissions. It provides many important principles, including the principle of "common but differentiated responsibilities", which has catered fully the interest of the developing countries. However, it is only a framework Convention, the task of elaborating concrete measures to implement the objectives and principles of the Convention, are subject to domestic laws, future negotiations and legislations of or among the involved parties. The Third Conference of the Parties in 1997 adopted the implementation file as "the Convention" Kyoto Protocol "(hereinafter referred to as the "Protocol"). If the Convention is named as the world's first country cooperation framework of a multilateral treaty on climate change, then the Protocol would be called the first fire in forms of treaty in all mankind to take on the implementation of the systematic obligations to the earth.

\footnotetext{
9 Yang Dongping, China's environmental development report (2010), Beijing: Social Sciences Documents Press, 2010, 43.
} 
The Kyoto Protocol clearly defines all the countries' responsibilities on greenhouse gas control. The specific provisions are: (1) Based on the emissions of 1990, the emissions of all the 38 counties listed in the Annex to be reduced by $5.2 \%$, while the EU by $8 \%$, the U.S. by $7 \%$, Japan and Canada by $6 \%$, and Eastern European countries by $5 \%-8 \%$. (2) Russia, Ukraine, New Zealand to maintain zero growth. (3) Due to the low original emissions, Australia's and Iceland's emissions to limit the growth of $8 \%$ and $10 \%$, respectively. (4) No indexed reduction requirements for developing countries, but national or regional planning expected in appropriate cases so as to improve emissions targets and patterns.10 The Protocol also creatively provides for three flexible mechanisms: the emissions trading mechanisms, the Clean Development Mechanism and the Joint Implementation mechanism. This category and targeted provision fully reflects the principle of "common but differentiated responsibilities." But the United States, for economic and financial considerations, withdrew from the Protocol in 2001 on the grounds that some of the developing countries with large amount of emissions are not included in the list to bear the responsibility for emissions reductions. The Protocol did not reinstall its effectiveness until it was signed by Russia in 2005.

In 2007 the Bali climate talks achieved the "multilateral political rare victory and subsequently reached the" Bali roadmap", which insists that all participating parties to achieve the long-term global emissions reduction goal in accordance with the principle of "common but differentiated responsibilities," and to make important progress in the following areas: (1) it explicitly requires all developed country Parties of the Convention to fulfill a measurable, reportable and verifiable greenhouse gas emission

${ }^{10}$ Yang Jiemian, The world's climate diplomatic and China's deal with, Beijing: Current Affairs Press, 2009, 45. 
reduction responsibility, which included U.S.A.; (2) it emphasizes the three neglected issues: adaptations to climate change, technology development and transfer issues, and funding issues. These three issues are of great interests to the majority of the developing countries; (3) it sets the "two-track-negotiations": on one hand it requires the developed countries who signed the Protocol to carry out the provisions of the Protocol, and to set a commitment to substantially quantified emission reduction targets after 2012; on the other hand, the developing countries and the countries have not signed the Protocol (mainly refer to the United States) are required to take further measures to address climate change under the Convention. ${ }^{11}$

This progress is a new annotation of the principle of "common but differentiated responsibilities". Subsequently, in the 2009 Copenhagen summit, Denmark Drafted attempts to transcend the "Bali roadmap" authorized "dual track" negotiations and to promote the "merged" obliterate the distinction of the responsibilities beared between the developed and the developing countries. During the Cancun summit in 2010, the Kyoto Protocol working group negotiations stagnated. One of the reasons is the representative of Japan declared in different occasions that Japan will never undertake any emission reduction targets from the second stage of the Protocol. The reason for which Japan opposed the Kyoto Protocol is that the Kyoto Protocol only covers $27 \%$ of the global emissions, while two of the world's biggest greenhouse gas emitter, the United States and China are not in the framework of the Protocol' commitment to reduction row of the target. This is exactly the same reasons that the United States launched the "Kyoto Protocol". It is noteworthy that, before the Cancun meeting, the

11 Ban Heping, "Reading the Bali Roadmap," Current event material manual, 2008, 38-39. 
nine-industry alliance from Japan has jointly put pressure on the Japan Government and required the Government to oppose the continuation of the Protocol. ${ }^{12}$ Therefore, Japan's move is likely for the maintenance of the economic interests, rather than the so-called international justice.

The developed countries' challenge on the principle of the "common but differentiated responsibilities" principle must not become a reason to shake the principle of distributive justice in the climate negotiations. Climate change negotiations should be concerned about the global common interests, but must give full consideration to the vulnerable side of the developing countries especially small island States and the least developed countries, the inlanded countries, the African countries - the stage of development and their basic needs. ${ }^{13}$ China is the world's largest developing country; taking care of its own problems well is the greatest contribution to the world. To this end, the Chinese government promulgated in 2007 the "China National Climate Change reframe, and on the eve of the Copenhagen summit, puts forward the target to reduce carbon emissions per unit of GDP in 2020 than in $200540 \%-45 \%$. Chinese government for its own good reduction condition, is willing to give priority of abatement assistance to poor countries. This is a necessary action of a responsible big country, and reflects its international morality. However, China's emissions are voluntary mitigation actions so it cannot be linked with the Western developed countries' mandatory

12 International online, "Japan never promised emission reduction goals international climate negotiations prospects are grim" [EB/OL]. http://gb.cri.cn/27824/2010/12/02/ 5187s3076351.htm, 2010-12-02.

${ }^{13} \mathrm{Hu}$ Jintao, "At the United Nations climate change summit opening ceremony speech" [EB/OL].http://news.xinhuanet.com/world/2009-09/23/ content_12098887.htm, 2009 -09-23. 
emission reduction obligations. Although China's total economic scale now ranks the second in the world, its per capita GDP is ranked behind the world's top 100, and about 150 million people are living below the poverty line, its economic development to improve the livelihood is still a very heavy task. ${ }^{14}$ China can enhance the transparency of emission reduction under the conditions that the developed countries provide financial and technical assistance, but cannot make reduction commitments inconsistent with its national conditions.

\section{References}

Bellamy, Foster John, Marx's ecology-materialism and nature, Liu Ren Sheng, et al., Beijing: Higher Education Press, 2006.

Ceng Jian Ping, Environmental justice-developing countries environmental ethics problems probing, Jinan: Shandong Peoples Publishing House, 2007.

Jing, Ma, The legal philosophy research of environmental justice, Changchun: Jilin University, 2005.

Mao, Yan Zuo, Environment of thought-environment protection and the Marxist attaches, Han Li Xin, et al. Japan: Cambridge University Press, 2006.

Tao Yang, Wang, From assigned to admit-environmental justice, Beijing: Tsinghua University, 2006.

Wens, Peter S., Temperature watts. Environmental justice theory, Zhu Dan Qiong et al., Shanghai: Shanghai People's Publishing House, 2007.

Zhang Bin, Environmental justice theory and practice research, Changsha: Hunan Normal University, 2009.

${ }^{14}$ Wang Hongbin, "The Chinese government response to climate change the position of the claim", Current event material manual, 2010, 18. 
Yang Jie Mian, The world's climate diplomatic and China's deal with, Beijing: Current Affairs Press, 2009.

Wang Tao Yang, Environmental justice-the reality of development of contemporary environment ethics trend, Journal of Zhejiang Province, 2002,5 .

Wang Tao Yang, Western environmental justice review study, Morality and Civilization, 2010, 1.

Zhang-bin, Chen Xue Qian, Environmental justice review study, Ethics Research, 2008, 4. 